\title{
The Brexit impact on European market co-movements
}

\author{
Hachmi Ben Ameur ${ }^{1}$ D $\cdot$ Waël Louhichi ${ }^{2}$
}

Accepted: 8 December 2020 / Published online: 3 January 2021

(c) The Author(s), under exclusive licence to Springer Science+Business Media, LLC part of Springer Nature 2021

\begin{abstract}
The aim of this paper is to investigate the impact of Brexit on the dependence between European financial markets. We use the Diebold and Yilmaz (2009, 2012) approach to better map the relationship between the three main European markets and we propose an Optimal portfolio weighting to gain insights into the portfolio design dynamics in the period between 2013 and 2019, in particular any changes due to uncertainty surrounding Brexit. First, the findings show that between September 2015 and September 2016, the high level of volatility and spillover confirms the strong degree of market integration, with uncertainty surrounding the referendum outcome having a clear impact on the three main European markets. Second, the direction of spillover in the pre-Brexit period was from the UK market to the French and German markets in anticipation of uncertainty regarding the outcome of the referendum and the period immediately following it. Third, only the conditional correlation between the pair (CAC40-FTSE100) is characterized by an asymmetric effect.
\end{abstract}

Keywords Financial time series · Asymmetric dependence $\cdot$ Volatility spillover $\cdot$ Brexit

JEL Classification C32 $\cdot$ G15 $\cdot$ E44

\section{Introduction}

On 23rd June 2016, the United Kingdom (UK) organized a referendum on whether or not to remain in the European Union (EU). 51.9\% of voters voted in favour of Brexit. The decision to leave the EU had several consequences on the regulatory and supervisory frameworks and hence on European economic integration. Before its withdrawal, the UK was one of the most important members of the European Single Market. Following a report from the European Commission "An Assessment of the Economic Impact of Brexit on the EU27 ", the partnerships between France, Germany and UK in 2015 were as follows: the

Hachmi Ben Ameur

hechba@yahoo.fr

1 INSSEC Grande Ecole, Paris, France

2 ESSCA School of Management, Angers, France 
largest volume of service exports to the UK are from France ( $€ 18$ billion) and Germany (€12 billion). On the import side, the picture is similar as Germany and France are in leading positions. The largest exporter is Germany ( $€ 68$ billion) followed by the Netherlands ( $€ 34$ billion) and France ( $€ 28$ billion) while the largest importer is Germany ( $€ 34$ billion) followed by France ( $€ 20$ billion). In 2018, exports to the EU accounted for $45 \%$ of all UK exports, and imports from the EU accounted for $53 \%$ of all UK imports. Brexit entails establishing barriers to the exchange of goods, capital and people between the UK and the remaining EU countries. The resulting economic disintegration will then lead to financial disintegration as regulations against free capital movement will inevitably have an impact on the financial sector and the way the financial markets operate. This view is confirmed by empirical observations which show that the day after Brexit, the FTSE 250 index plunged $7.2 \%$ and the pound sterling fell sharply by more than $8 \%$ against the US dollar and $6 \%$ against the euro.

The aim of this paper is to investigate the impact of Brexit on the interdependence between the UK stock market and the stock markets in the remaining EU member countries. Our study on stock market dependence examines whether shocks in one market are transmitted to other markets, assessing the degree of dependency between the European financial markets both before and after Brexit. The aim is to test whether European economic disintegration leads to a decline in the integration of European financial markets. It is vital for European policymakers to understand the issues at stake in order to introduce appropriate regulations, as should investors who wish to develop international diversification and hedging strategies. In fact, international diversification and systemic risk is reduced only if the markets are not dependent (Bekaert et al. 2005).

Several papers have investigated the dependence between financial markets with respect to major events, especially around crisis events. These studies invoke the concept of contagion introduced by Forbes and Rigobon (2002). According to the authors, contagion describes a situation where there is an increase in cross-market dependence following an exogeneous shock that cannot be explained by fundamentals. The hypothesis of contagion has been tested with respect to many events. Arshanapalli and Doukas (1993) highlighted an increase in dependence between the U.S. market and European markets following the crash of October 1987. Yang et al. (2003) showed that the Asian stock markets and the US market became more correlated during the Asian financial crisis of 1997. Jawadi et al. (2015) tested the contagion hypothesis on the subprime crisis. They demonstrated an increase in volatility spillover from the US to the three largest European markets (Frankfurt, London and Paris) and vice versa during the post-crisis period. Recently, Aristeidis and Elias (2018) used a copulas approach to investigate the international markets' reaction to the results of the UK's referendum. They found a price reversal a few days after the date of the referendum, allowing the stock markets to recover their losses.

Our study is related to the above literature as we test the dependence between the London stock exchange and the largest European financial stock markets both before and after Brexit. Our contribution examines the data used, the methodology adopted, and the result obtained. Fetzer (2019) shows that the outcome of this vote was the result of a long term policy, suggesting that austerity policies from late 2010 onward are key to understanding the Brexit. Unlike Aristeidis and Elias (2018), who considered a period of study covering 6 months before the polling day and 6 months after article 50 of the Lisbon Treaty was triggered, and Belke et al. (2018), who considered the policy uncertainty impact linked to the Brexit on the UK financial market until May 2016, we test the stability of interdependence between the European financial markets 3 years before (pre-Brexit period) and 3 years after the UK's referendum (post-Brexit period). In fact, the market reaction to a complex 
event such as Brexit can take a long time and needs to be examined over the long term. In this study, we consider the family of GARCH models and use the methodology of Diebold and Yilmaz $(2009,2012)$ to investigate the interdependence and spillover effects across the three main European financial markets (the UK, Germany and France). This approach gives a breakdown of the variance in rich information from the spillover dynamics as it enables us to distinguish the part of variation in the dynamics of a time-dependent variable due to its own shocks from those that occur in a knock-on effect from other variables. This methodology has the advantage of transforming a large volume of information into a single quantitative measure called the spillover index. Overall, our approach enables us to develop a better understanding of the relationship between the three main European financial markets in terms of returns and volatility spillover, especially during the Brexit period. Our results highlight a high level of volatility and spillover in the period from September 2015 to September 2016, which confirms the high level of integration between the three markets and the impact on these markets from the uncertainty surrounding the referendum outcome. Finally, it is worth noting that the direction of spillover during the pre-Brexit period was from the UK market to the French and German markets due to the uncertainty of the outcome of the referendum and the period immediately following it.

The rest of the paper is organized as follows. Section 2 presents our data and methodology. Section 3 details our results and the last section concludes.

\section{Methodology}

In the following sub-section, we provide a brief review of the econometric approaches used in this study to estimate the spillover index of Diebold and Yilmaz (2009, 2012). We used the daily logarithmic difference of the closing prices to compute the return spillover index. For daily volatility, we used the GARCH framework and then the ADCC-GARCH model to determine the time-varying correlation between the different markets and to analyse the impact of Brexit on European market integration. At the end of the empirical investigation, we put forward an analysis of the optimal portfolio using the results of the dynamic correlations. The goal is to analyse the diversification effect in order to help investors to manage their portfolios, taking into consideration the Brexit risk.

\subsection{Stock price volatility and correlation dynamics}

We first computed the daily market returns as the logarithmic difference of prices:

$$
\text { return }_{i t}=\log \left(P_{i t} / P_{i t-1}\right) \times 100
$$

where $P_{i t}$ and $P_{i t-1}$ are the closing prices for day $t$ and day $t-1$ and $i$ represents the UK, Germany and France.

In order to reproduce time-variation of market price volatility, we used the EGARCH model. The EGARCH model is popular as, among other reasons, it can capture asymmetry and leverage effects. The leverage effect refers to the correlation between increases in volatility due to negative shocks to returns and decreases in volatility due to positive shocks to returns. Several studies have shown the relevance of the asymmetric GARCH model in estimating conditional volatility. Chen and Kuan (2002) applied the modified CCK test of Chen (2001) to compare several conditional volatility models, accepting only the EGARCH for a number of index prices. In similar vein, 
Poon and Granger (2003) compared several studies related to GARCH models and concluded that asymmetric conditional volatility estimation models such as EGARCH outperform symmetric estimation models.

In this paper, we considered the EGARCH model which accounts for asymmetry in conditional variance of returns since bad news has a greater impact than good news. Formally, we noted a vector of $i$ European market return by $r_{i, t}$ and specified its dynamics as follows:

$$
r_{i, t}=\mu_{i}+\varepsilon_{i, t},
$$

where $r_{i, t}$ denotes the returns vector, $\mu_{i}$ is a constant and $\varepsilon_{i, t}$ is an error term at time $t$ for the corresponding market $i$.

$$
\varepsilon_{i, t}=H_{i, t}^{1 / 2} z_{i, t},
$$

where $H_{i, t}$ is a matrix of conditional covariances of $\varepsilon_{i, t}, z_{i, t}$ is i.i.d. $(0, \mathrm{I})$, and I denotes the identity matrix.

$$
\ln \left(\sigma_{i, t}^{2}\right)=\omega_{i}+\beta \ln \left(\sigma_{i, t-1}^{2}\right)+\gamma \frac{\varepsilon_{i t-1}}{\sqrt{\sigma_{i, t-1}^{2}}}+\alpha\left[\frac{\left|\varepsilon_{i, t-1}\right|}{\sqrt{\sigma_{i, t-1}^{2}}}-\sqrt{\frac{2}{\pi}}\right],
$$

where $\omega, \beta, \gamma$ and $\alpha$ are parameters to be estimated for each $i$ market.

To enable correlations and variances to vary over time, several multivariate GARCH specifications were developed. The ADCC model proposed by Cappiello et al. (2006) is distinguished by its simplicity, as the algorithm execution procedure is conducted in two steps. Thus, it offers a suitable framework for improving the estimate of the conditional variance and conditional correlation. We estimated the time-varying standard deviation of the series considered in this paper by using the EGARCH model defined in the equation in the first step (3) and the time-varying correlation matrix in the second step. The parameters for the conditional correlation were estimated, taking into consideration the parameters from the first step.

The conditional variance $\mathrm{H}_{\mathrm{t}}$ of $\varepsilon_{\mathrm{t}}$, which is the innovation with the ADCC specification, can be expressed as follows:

$$
H_{t}=D_{t} R_{t} D_{t},
$$

where Rt and Dt are the matrix of conditional correlation of the standardised residuals, and the diagonal matrix of time-varying standard deviations respectively. The conditional correlation of the ADCC model is defined as follows:

$$
Q_{t}=\left(1-\theta_{1}-\theta_{2}\right) \bar{Q}-\theta_{3} \bar{N}+\theta_{1}\left(\varepsilon_{t-1} \varepsilon_{t-1}^{\prime}\right)+\theta_{3}\left(e_{t-1} e_{t-1}^{\prime}\right),
$$

where $\theta_{1}, \theta_{2}$, and $\theta_{3}$ measure the effects of shocks, dynamic correlations and the asymmetric effect, respectively. $\bar{Q}$ represents the unconditional and time-invariant variance-covariance matrices of the standardised residuals $\varepsilon_{t}, e_{t}=I\left(\varepsilon_{t}<0\right)^{\circ} \varepsilon_{t}$ (where ${ }^{\circ}$ denotes the Hadmard product element-wise matrix multiplication). The term $\bar{N}=E\left(e_{t-1} e_{t-1}^{\prime}\right)$ captures the periods when there is a negative shock for both markets. 


\subsection{The Diebold and Yilmaz index}

Several approaches were used to measure the spillover effect between financial markets. We can cite the contagion model of King and Wadhwani (1990) based on the signal extraction method, the global factor approach of Pukthuanthong and Roll (2009) that measures integration through time, the Granger-causal networks of Billio et al. (2012) and the generalized impulse response based spillovers of Alter and Beyer (2014) which can be seen as the extreme amplification of spillover effects. Diebold and Yilmaz (2009, 2012) approach is distinguished by the fact that it focus on the variance decompositions and shows how it is possible to aggregate spillover effects in markets by gathering a large amount of information into a single spillover measure. In the line with the work of Koop et al. (1996) and Pesaran and Shin (1998), Diebold and Yilmaz (2012) use a generalized VAR framework. The generalized framework brings an important innovation in that it allows correlated shocks to be appropriately addressed using the historically observed distribution of the errors.

Diebold and Yilmaz (2009) proposed spillover measures based on forecast error variance decompositions from the orthogonalized impulse response function. This measure of the return and volatility spillovers uses vector autoregressive (VAR) models and allows us to decompose the variance to get rich information from the spillover dynamics. Diebold and Yilmaz (2012) improved their method by using a generalized vector autoregressive model where forecast-error variance decompositions are invariant to variable ordering. This approach helps to address the limitation of the first version of the Diebold and Yilmaz (2009) model with the order-dependent results due to the use of the Cholesky factor orthogonalization.

Let us consider the $\mathrm{N}$-variable $\operatorname{VAR}(\mathrm{p})$ specification given by:

$$
x_{t}=\sum_{t=1}^{P} \phi_{i} x_{t-i}+\varepsilon_{t}
$$

where $x_{t}$ can be a vector of asset returns or return volatilities, $\varepsilon_{t}$ a vector of independently and identically distributed residuals and $\phi_{i}$ the model parameters to be estimated.

Under the assumption of covariance stationarity, the VAR defined in the Eq. (1) can be rewritten in a moving average representation as:

$$
x_{t}=\sum_{t=1}^{\infty} A_{i} \varepsilon_{t-i}
$$

where $A_{i}$ are the coefficients of the $N \times N$ matrix, $A_{i}$ is followed by the recursion $A_{i}=\phi_{1} A_{i-1}+\phi_{2} A_{i-2}+\ldots+\phi_{p} A_{i-p} . A_{0}$ is an identity matrix, and $A_{i}=0$ for $i<0$.

The generalized VAR model used by Diebold and Yilmaz (2012) allows us to express the H-step-ahead generalized forecast-error variance decomposition. The latter defines the eigen-variance share as part of the H-step-ahead error variance in anticipating $x_{i}$ due to the shocks to $x_{j}$, and spillovers as part of the H-step-ahead error variance in anticipating $x_{i}$ due to the shocks to $x_{j}$, for $i, j=1,2, \ldots N$, such that $i \neq j$. Then, using the generalized VAR framework of Koop et al. (1996) and Pesaran and Shin (1998), the H-stepahead generalized forecast-error variance decomposition denoted as $\theta_{i j}^{g}(H)$ is expressed as: 


$$
\theta_{i j}^{g}(H)=\frac{\sigma_{j j}^{-1} \sum_{h=0}^{H-1}\left(e_{i}^{\prime} A_{h} \Sigma e_{j}\right)^{2}}{\sum_{h=0}^{H-1}\left(e_{i}^{\prime} A_{h} \Sigma A_{h}^{\prime} e_{i}\right)}
$$

where $\Sigma, \sigma_{j j}$ and $e_{i}$ are respectively the variance matrix for the error vector $\varepsilon$, the standard deviation of the error term for the $j$ th equation and the selection vector with 1 as the $i$ th element and 0 otherwise.

Each entry of the variance decomposition matrix is then normalized by the sum of the elements of each row of the variance decomposition table as:

$$
\tilde{\theta}_{i j}^{g}(H)=\frac{\theta_{i j}^{g}(H)}{\sum_{j=1}^{N} \theta_{i j}^{g}(H)}
$$

Diebold and Yilmaz (2012) use the Koop et al. (1996) and Pesaran and Shin (1998) variance decomposition approach to determine the total spillover index (TS). This approach solves the ordering problem that arose in the Diebold and Yilmaz (2009) model. The TS index can measure the contribution of the spillover of shock returns or volatility across different variables to the total forecast error variance. The TS index is expressed as follows:

$$
T S(H)=\frac{\sum_{i, j=1}^{N} \tilde{\theta}_{i j}^{g}(H)}{\sum_{i, j=1}^{N} \tilde{\theta}_{i j}^{g}(H)} 100=\frac{\sum_{\substack{i, j=1 \\ j \neq i}}^{N} \tilde{\theta}_{i j}^{g}(H)}{N} 100
$$

Moreover, with this approach it is possible to calculate the directional $y$ spillover (DS) on the basis of the normalized elements of the variance decomposition matrix. This allows us to map the direction of spillovers across different variables, making it possible to measure volatility spillovers received by variable $i$ from all other variables $j$ and in the opposite direction, as well as the spillover from the variable $i$ to all other variables $j$. The DS measure is expressed as follows:

The DS to measure spillovers received by variable $i$ from all other variables $j$ is written as:

$$
D S_{i \leftarrow j}(H)=\frac{\sum_{j=1}^{N} \tilde{\theta}_{i j}^{g}(H)}{\sum_{i, j=1}^{N} \tilde{\theta}_{i j}^{g}(H)} \times 100=\frac{\begin{array}{c}
\sum_{j=1}^{N} \tilde{\theta}_{i j}^{g}(H) \\
j \neq i
\end{array}}{N} 100
$$

The DS to measure spillover from the variable $i$ to all other variables $j$ is written as:

$$
D S_{i \rightarrow j}(H)=\frac{\substack{\sum_{j=1}^{N} \tilde{\theta}_{j i}^{g}(H) \\ j \neq i}}{\sum_{i, j=1}^{N} \tilde{\theta}_{j i}^{g}(H)} \times 100=\frac{\substack{\sum_{j=1}^{N} \tilde{\theta}_{i j}^{g}(H) \\ j \neq i}}{N} 100
$$

The net spillover (NS) allowing us to estimate the contribution for the variation of the variable $i$ to the other variables $j$ is written as:

$$
N S_{i}(H)=D S_{i \rightarrow j}(H)-D S_{i \leftarrow j}(H)
$$


Finally, the net pairwise spillover (NPS) allows us to measure the difference between the gross shocks transmitted from the variable $i$ to the variables $j$ and those transmitted from the variables $j$ to the variable $i$. This measure is expressed as follows:

$$
N P S_{i j}(H)=\left(\frac{\tilde{\theta}_{j i}^{g}(H)}{\sum_{i, k=1}^{N} \tilde{\theta}_{i k}^{g}(H)}-\frac{\tilde{\theta}_{i j}^{g}(H)}{\sum_{j, k=1}^{N} \tilde{\theta}_{i k}^{g}(H)}\right) \times 100=\left(\frac{\tilde{\theta}_{j i}^{g}(H)-\tilde{\theta}_{i j}^{g}(H)}{N}\right) \times 100
$$

\section{Empirical results}

\subsection{Data}

The aim of this paper is to investigate the dependence between the London stock exchange and the main European financial stock markets over Brexit. We chose the German market (DAX 30) and the French market (CAC40) as they are the largest economies and the biggest financial markets in Europe. They are also the most important countries with which the UK has an economic relationship. We broke down our period of study into two periods: 3 years before the 23rd of June 2016 (pre-Brexit period) and 3 years after this date (postBrexit period). We chose this period of study in order to avoid including the subprime crisis in the period before Brexit and to avoid contaminating our post-Brexit period with the Covid-19 crisis.

Figure 1 clearly shows the impact of anticipation of the referendum in June 2016. All three figures of the return series highlight a high level of positive and negative returns starting in June 2015, which shows that the markets were anticipating the uncertainty of the referendum result. Table 1 reports the main statistical properties based on the returns' series plotted in Fig. 1. Regarding the means, the DAX 30 exhibits the highest mean returns in comparison to the CAC40 and the FTSE 100. In terms of standard deviation, the FTSE 100 shows the lowest level during the whole period, while the CAC40 and the DAX 30 were at virtually the same level. During the period of investigation, the maximum drop was experienced by the CAC40, where the highest positive return was for the DAX 30. Skewness is often negative and statistically significant during this period for all three indices. The Kurtosis suggests that the distribution tails for the three series are higher than those of a normal distribution. Finally, using the Jarque-Bera test, normality is statistically rejected for the three series considered in this paper.

\subsection{Time-varying relation between the UK, France and Germany}

Table 2 reports the EGARCH parameters estimation for the period from June 2013 to June 2019. The parameters $\alpha$ and $\beta$ are significant for the three series, which indicates that the conditional volatility at time $t$ is impacted by the conditional volatility of $t-1$ as well as by new information arriving on the markets. The high $\beta$ value slightly inferior to 1 observed for the three markets returns reflects the long-term memory, i.e., the phenomenon of persistence in the volatilities of these market returns. The significance of $\alpha$ means that information arriving on these markets will have a greater impact on conditional volatility. The $\gamma$ parameter captures the leverage effect, negative correlation between returns shocks and subsequent shocks to volatility. The $\gamma$ parameter is significant for all three markets. In other 

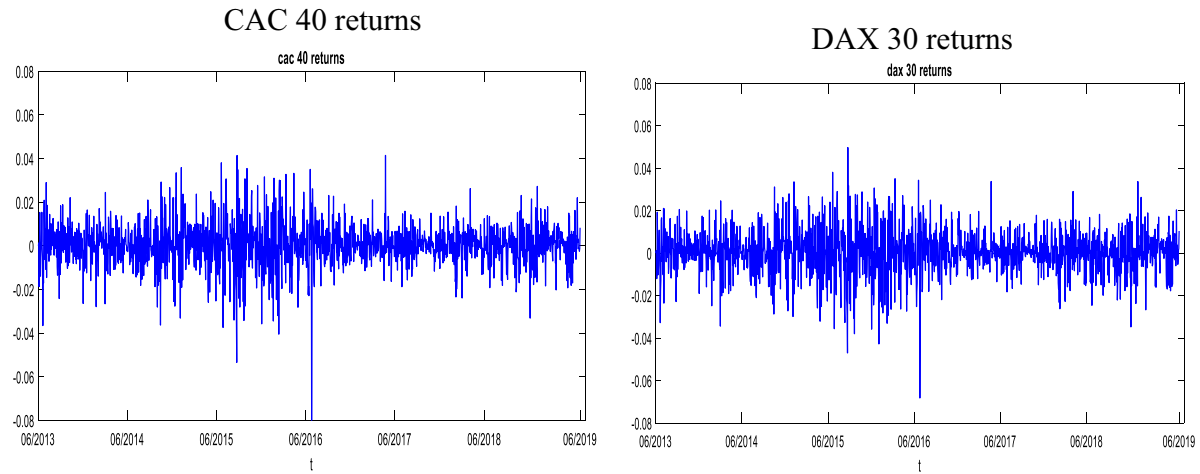

FTSE100 returns

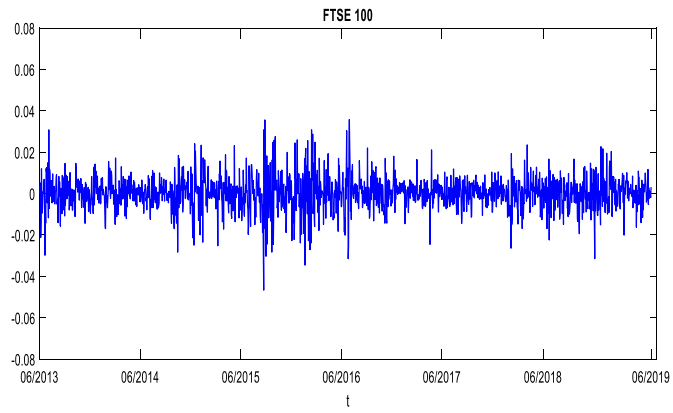

Fig. 1 Returns index series

Table 1 Descriptive statistics

\begin{tabular}{lccc}
\hline & CAC 40 returns & DAX 30 returns & FTSE100 returns \\
\hline Mean & 0.000273 & 0.000312 & 0.000116 \\
Median & 0.000180 & 0.000470 & 0.000129 \\
Maximum & 0.041439 & 0.049717 & 0.035775 \\
Minimum & -0.080425 & -0.068233 & -0.046670 \\
SD & 0.010458 & 0.010775 & 0.008302 \\
Skewness & -0.377227 & -0.286956 & -0.126141 \\
Kurtosis & 7.028737 & 5.372542 & 5.647342 \\
Jarque-Bera & 1109.495 & 393.4982 & 467.0509 \\
Probability & 0.000000 & 0.000000 & 0.000000 \\
\hline
\end{tabular}

words, volatility in these markets increases more after a negative shock than after a positive shock of the same magnitude.

Figure 2 shows the volatilities for the FTSE 100, the CAC40 and the DAX 30. Interestingly we can note that anticipation of the referendum of June 2016 led to increased volatility, and therefore a risk for all three markets. The referendum effect is clearly visible in Fig. 2, with the highest level of volatility during the period from June 2015 to September 2016. The results also indicate that conditional volatility for the CAC40 is significantly higher than that of the FTSE 100 and the DAX 30. 
Table 2 EGARCH parameters

\begin{tabular}{lccc}
\hline & CAC 40 returns & DAX 30 returns & FTSE100 returns \\
\hline$\mu$ & & & \\
Coeff & $8.83 \mathrm{E}-05$ & 0.000222 & -0.000157 \\
Prob & 0.6728 & 0.3113 & 0.3682 \\
$\Omega$ & & & \\
Coeff & -0.4043 & -0.3729 & -0.5630 \\
Prob & 0.0000 & 0.0000 & 0.0005 \\
$\alpha$ & & & 0.1256 \\
Coeff & 0.121841 & 0.110208 & 0.0011 \\
Prob & 0.0022 & 0.0008 & -0.1591 \\
$\gamma$ & & & 0.0000 \\
Coeff & -0.1582 & -0.1094 & 0.9530 \\
Prob & 0.0000 & 0.0000 & 0.0000 \\
$\beta$ & & & 5535.358 \\
Coeff & 0.9665 & 0.9685 & \\
Prob & 0.0000 & 0.0000 & \\
Log L & 5171.061 & 5076.180 & \\
\hline
\end{tabular}

**** Significant at $p<0.01$; **significant at $p<0.05$; *significant at $p<0.1$
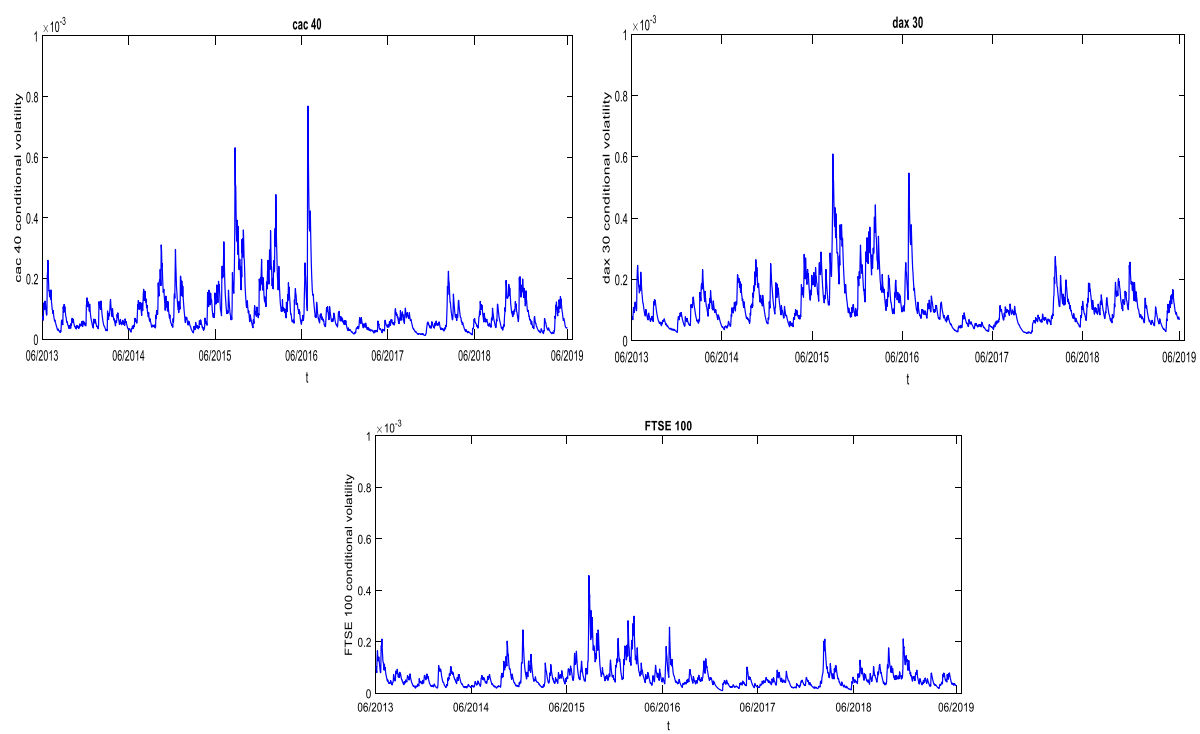

Fig. 2 Volatility Series plots for France, Germany and the UK

Table 3 presents the estimation of parameters of conditional covariance. $\theta_{1}$ indicates that the effect of shocks on conditional correlation between the three European markets is significant. The relationship seems to be stronger between the pairs (CAC40-DAX30) and (DAX30-FTSE100) than (CAC40-FTSE100). $\theta_{2}$ measures the dynamic correlations and 
Table 3 Estimation of conditional covariance parameters

\begin{tabular}{|c|c|c|c|}
\hline & CAC40-DAX30 & DAX30-FTSE100 & CAC40-FTSE100 \\
\hline \multicolumn{4}{|l|}{$\theta_{1}$} \\
\hline Coeff & 0.063621 & 0.064387 & 0.034974 \\
\hline Prob & 0.0066 & 0.0059 & 0.0000 \\
\hline \multicolumn{4}{|l|}{$\theta_{2}$} \\
\hline Coeff & 0.776155 & 0.850141 & 0.925482 \\
\hline Prob & 0.0000 & 0.0000 & 0.0000 \\
\hline \multicolumn{4}{|l|}{$\theta_{3}$} \\
\hline Coeff & 0.001111 & 0.002075 & 0.004582 \\
\hline Prob & 0.1082 & 0.4649 & 0.0002 \\
\hline Log-likelihood & $11,500.44$ & $11,185.56$ & $11,418.69$ \\
\hline
\end{tabular}

*** Significant at $p<0.01$; **significant at $p<0.05 ; *$ significant at $p<0.1$

is significant for all the market pairs. There is significant transmission between the three markets over the long term. In addition, the impact is positive and market volatilities vary in the same direction. $\theta_{3}$ measures the asymmetric effect. However, this parameter is only significant for the pair (CAC40-FTSE100). This confirms that the relationship between these markets is time-dependent and that the ADCC model is appropriate for this study.

Figure 3 presents the time-varying correlations between the three markets. The strongest relationship is between the pair (CAC40-DAX30), with the highest level of correlation around 0.9 during the whole period. This result confirms that the level of integration between the German and French markets is very strong. For the other pairs, (DAX30-FTSE100) and (CAC40-FTSE100), the relationship is more volatile. The
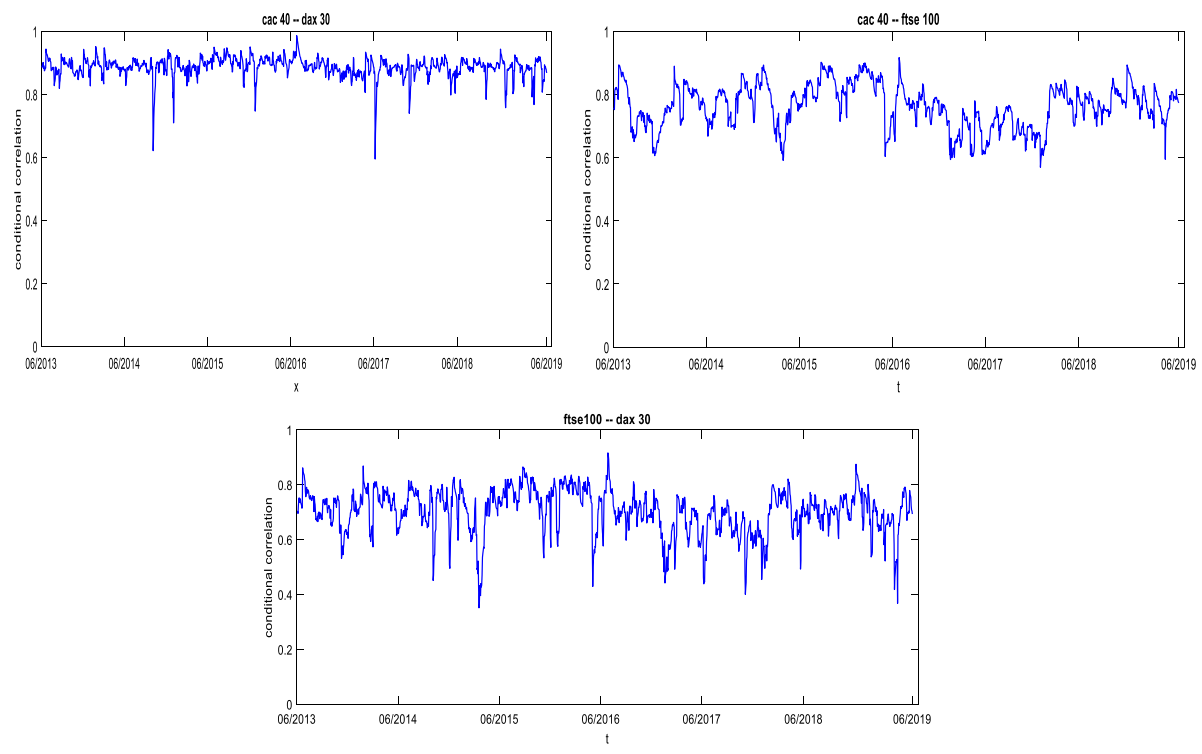

Fig. 3 Time-varying correlations between the French, German and UK index series 
Table 4 TS index and Net spillover of returns

\begin{tabular}{lllrr}
\hline & TVS index & \multicolumn{2}{l}{ Net spillover } & \\
\cline { 3 - 5 } & & FTSE 100 & CAC 40 & DAX 30 \\
\hline June 1, 2013 to June 23, 2016 & 0.6141 & 0.0294 & -0.0282 & -0.0012 \\
June 23, 2016 to June 30, 2019 & 0.5479 & -0.0551 & 0.0607 & 0.0056 \\
June 1, 2013 to June 30, 2019 & 0.5845 & -0.0037 & 0.0162 & 0.0001 \\
\hline
\end{tabular}

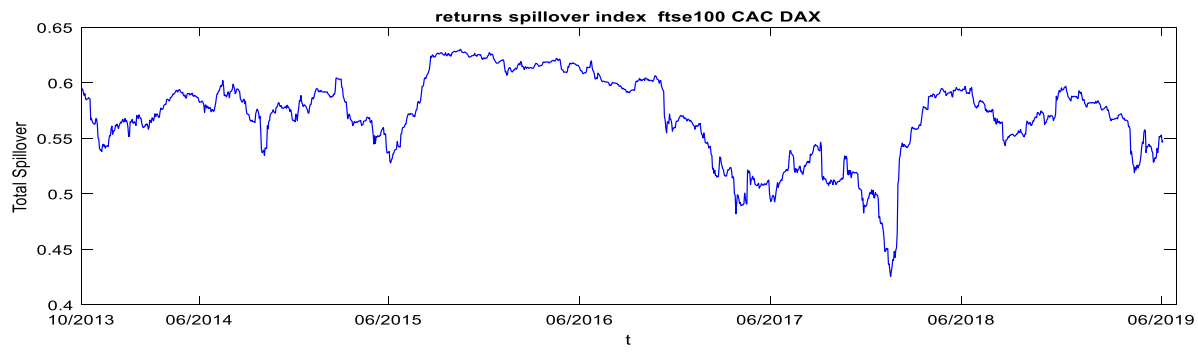

Fig. 4 Dynamic total spillover index for the returns of France, Germany and the UK. The values are calculated from the forecast error variance decompositions

conditional correlation oscillates between 0.5 and 0.85 for the pair (DAX30-FTSE100) and between 0.4 and 0.85 for the pair (CAC40-FTSE100).

\subsection{Return and volatility spillovers between the UK, France and Germany}

In this section we first focus on the empirical results for return spillover and then report the findings concerning volatility spillover following the approach of Diebold and Yilmaz (2009, 2012). For both cases, we estimate first the total spillover index (TS) from Eq. (10), which allows us to measure the contribution of the spillover of returns or volatility shocks across different variables to the total forecast error variance. Second, we compute the net spillover (NS) from Eq. (13), which allows us to estimate the volatility or returns contribution for the variable $i$ to the volatility or returns of the other variables $j$.

\subsubsection{The return spillover}

Table 4 reports the static total index and the static net spillover for the European market returns and then the dynamic total index and the dynamic net indexes in Figs. 4 and 5 respectively.

Table 4 shows that the TS index is higher for the first period before June 23, 2016, the date of the referendum. In Fig. 4, the highest level of TS is between September 2015 and September 2016. This period corresponds to the uncertainty surrounding the Brexit referendum. The high level of TS confirms the high level of integration of these markets and the fact that the uncertainty surrounding the outcome of the referendum had an impact on all three markets. The index remained at a high level until September 2016 and has gradually decreased since then. 

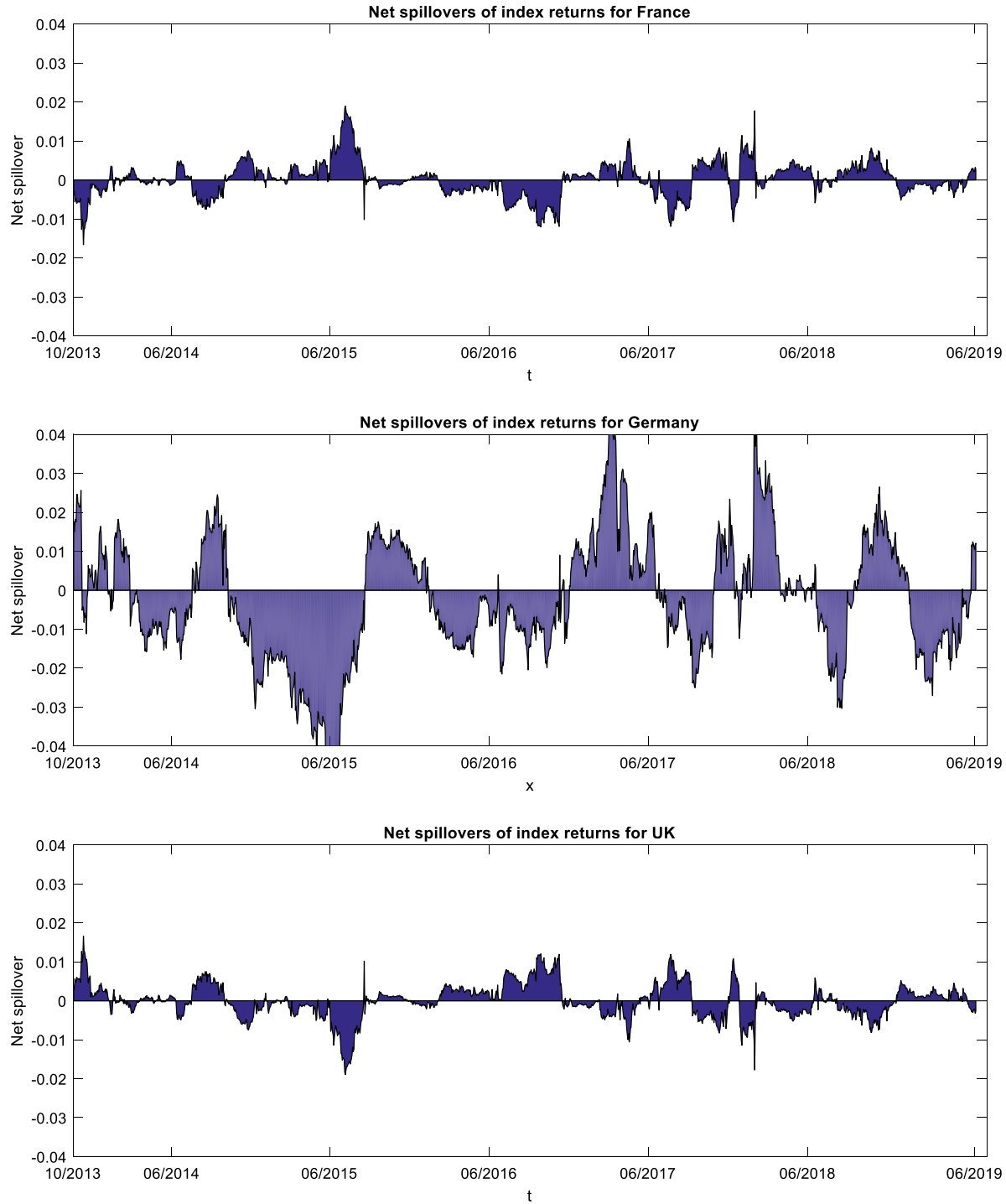

Fig. 5 Dynamic net spillover of index returns for France, Germany and the UK

The results of the net spillover for the return indexes are interesting. Recall that the net spillover is calculated as "the spillover to "minus" the spillover from". First, the net volatility spillover for the UK during the whole period is negative where the CAC40 is positive and the DAX 30 slightly greater than zero. This finding shows that over the whole period in question, it is the CAC40 that has a positive balance between what was communicated and what was received as spillover. Second, in the post-Brexit period, it was the FTSE 100 that transmitted more spillover than it received. Indeed, in Fig. 5, we can see that net spillover in 2016 is positive for the FTSE 100 and negative for the CAC40 and DAX 30, which shows that the spillover direction in this period was from the UK market to the French and 
Table 5 TS index and net spillover of index volatilities

\begin{tabular}{llllr}
\hline & TS index & \multicolumn{2}{l}{ Net spillover } & \\
\cline { 3 - 5 } & & UK & France & Germany \\
\hline June 1, 2013 to June 23, 2016 & 0.6219 & 0.0612 & -0.0612 & -0.0223 \\
June 23, 2016 to June 30, 2019 & 0.5613 & -0.1093 & 0.1131 & -0.0037 \\
June 1, 2013 to June 30, 2019 & 0.5713 & -0.09 & 0.0728 & 0.0232 \\
\hline
\end{tabular}

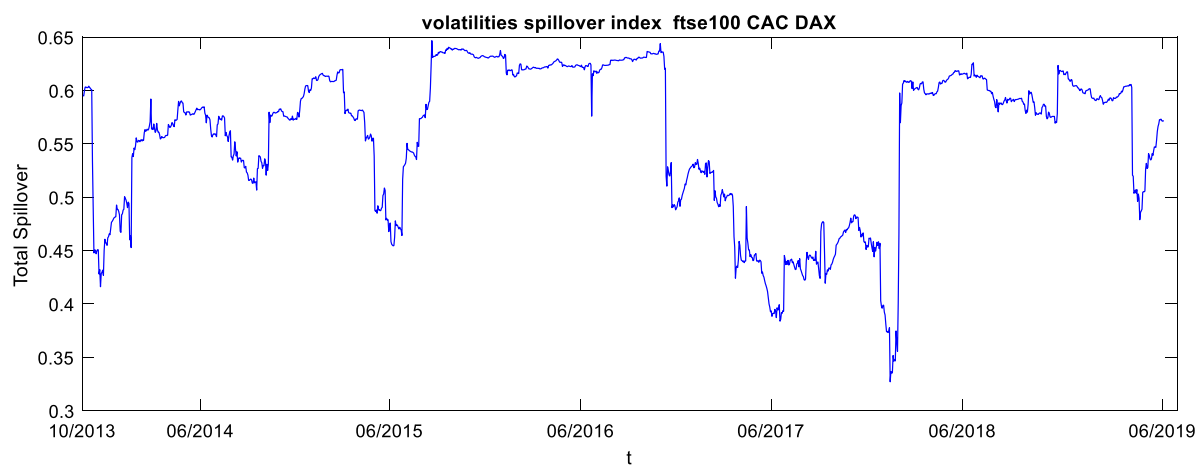

Fig. 6 Dynamic total spillover index for the volatilities of France, Germany and the UK. The values are calculated from the forecast error variance decompositions

German markets in anticipation of uncertainty about the outcome of the referendum and the period immediately following it.

\subsubsection{Volatility spillover}

In Table 5, we report the static total index and the static net spillover for the three European market volatilities, while in Figs. 4 and 5, we present the dynamic total index and the dynamic net indexes respectively.

In Table 5, Figs. 6 and 7, we can see that the results follow the same trend as the spillover of returns. However, it is interesting to note that the spillover levels of volatilities are higher with more abrupt changes. The highest level of the total spillover index is consistently observed around the date of the referendum. From March 2018, several events impacted the spillover between the three markets. Negotiations on the future relationship between the EU and the United Kingdom, the initially planned 29th March exit terms and conditions, and also the fact that no compromise was reached on the Irish border issue led to a new episode of volatility in all three markets. Conditional volatilities as well as the TS surged during this period. On June 12, 2018, the parliamentary process regarding the "withdrawal law", led to a period of uncertainty with the beginning of the "parliamentary ping-pong". Finally, Aristeidis and Elias (2018) used intraday data returns to highlight the contagion effect associated with the referendum date. The results of this study with the use of the approach by Diebold and Yilmaz $(2009,2012)$ extended the above work and allowed us to map this relationship in order to better understand the relationship between these markets over the course of our study period. 

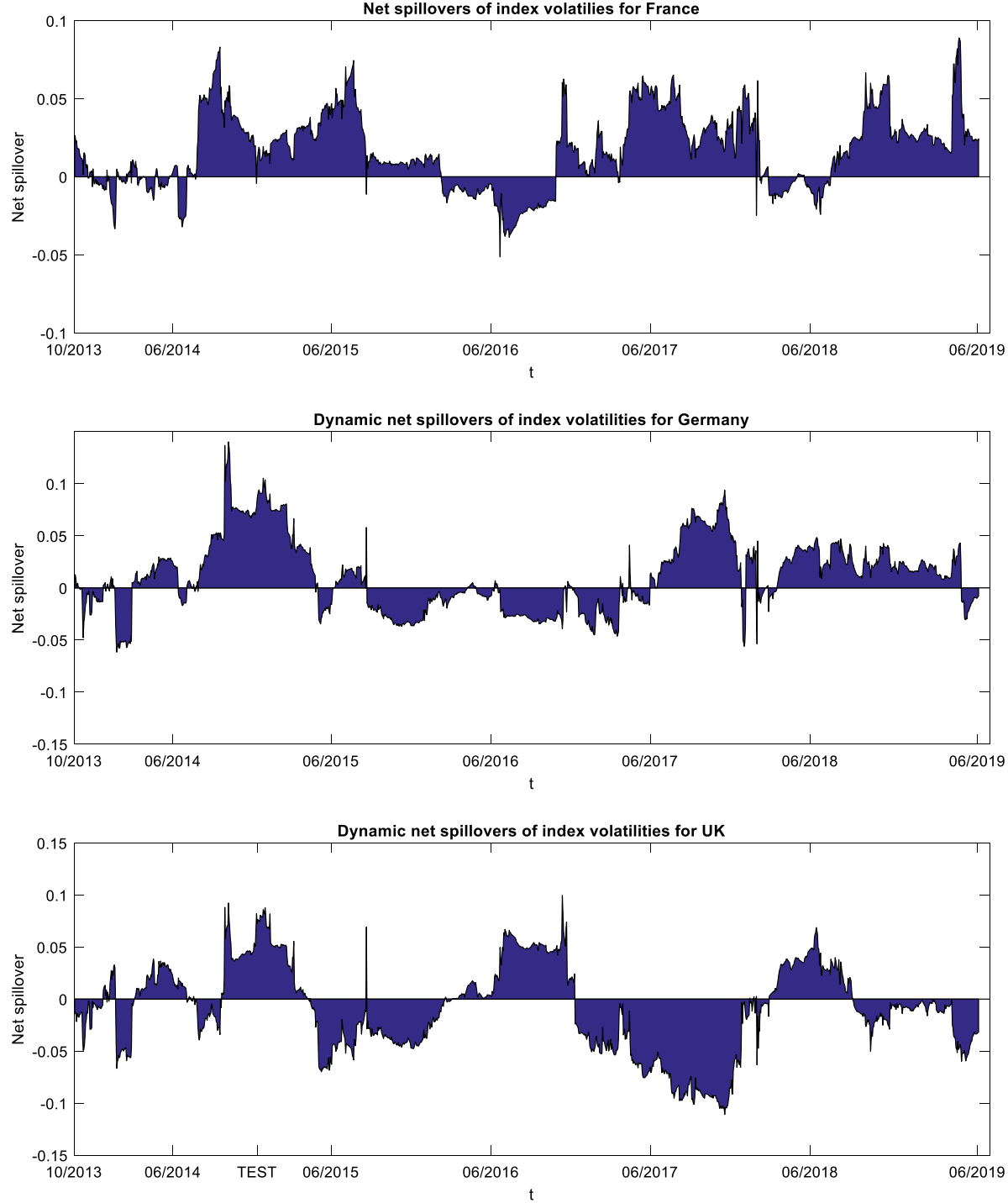

Fig. 7 Dynamic net spillover of index volatilities for France, Germany and the UK

\subsection{Optimal portfolio weights}

For this final section, we computed the optimal daily time-varying weights. The goal was to better understand the portfolio design dynamics during the 2013 and 2019 period, especially the changes due to the uncertainty surrounding Brexit.

The calculation of the optimal portfolio weights has been one of the most important issue in finance and risk management literature. The optimal portfolio weights can be determined by minimising the risk of the portfolio without impacting the expected returns. In his paper we consider the Kroner and $\mathrm{Ng}$ (1998) approach to calculate the optimal 
holding weights. This approach has important economic implications for building accurate asset pricing strategies. We assume that the investor holds a UK asset and wants to hedge his or her exposure against the uncertainty linked to Brexit during this period by considering asset $j$ (where $j$ can be France or Germany). Using the approach of Kroner and $\mathrm{Ng}$ (1998), the optimal portfolio weights are calculated as follows:

$$
\begin{aligned}
\mathrm{w}_{\mathrm{UK}, \mathrm{j}, \mathrm{t}} & =\frac{\mathrm{h}_{\mathrm{j}, \mathrm{j}, \mathrm{t}}-\mathrm{h}_{\mathrm{UK}, \mathrm{j}, \mathrm{t}}}{\mathrm{h}_{\mathrm{UK}, \mathrm{UK}, \mathrm{t}}-2 \mathrm{~h}_{\mathrm{UK}, \mathrm{j}, \mathrm{t}}+\mathrm{h}_{\mathrm{j}, \mathrm{j}, \mathrm{t}}} \\
\mathrm{W}_{\mathrm{UK}, \mathrm{j}, \mathrm{t}}= & \left\{\begin{array}{lll}
0, & \text { if } & W_{\mathrm{UK}, \mathrm{j}, \mathrm{t}}<0 \\
\mathrm{~W}_{\mathrm{UK}, \mathrm{j}, \mathrm{t}}, & \text { if } & 0 \leq \mathrm{W}_{\mathrm{UK}, \mathrm{j}, \mathrm{t}} \leq 1 \\
1, & \text { if } & W_{\mathrm{UK}, \mathrm{j}, \mathrm{t}}>1
\end{array}\right.
\end{aligned}
$$

where $\mathrm{W}_{\mathrm{UK}, \mathrm{j}, \mathrm{t}}$ represents the optimal daily weights invested in the FTSE 100 asset. $\mathrm{h}_{\mathrm{UK}, \mathrm{UK}, \mathrm{t}}, \mathrm{h}_{\mathrm{j}, \mathrm{j}, \mathrm{t}}$ and $\mathrm{h}_{\mathrm{UK}, \mathrm{j}, \mathrm{t}}$ are the conditional volatility of the FTSE 100, the conditional volatility of the index that completes the portfolio and the conditional covariance, respectively.

In terms of mean-variance analysis, the investors have to adapt their positions taking into account the optimal portfolio weights of Kroner and $\mathrm{Ng}$ (1998). However, investors should not rebalance their positions at every time $t$, as this can lead to a significant increase in transaction costs. Investors can take into account the average weightings of the components of a portfolio over a given period of time and rebalance the portfolio by buying the underweighted assets and selling the overweighted assets. From Fig. 8, we note that the optimal weights appear to be time-varying and change over the period 2013-2019. Clearly, from the beginning of 2016, uncertainty related to the referendum began to grow
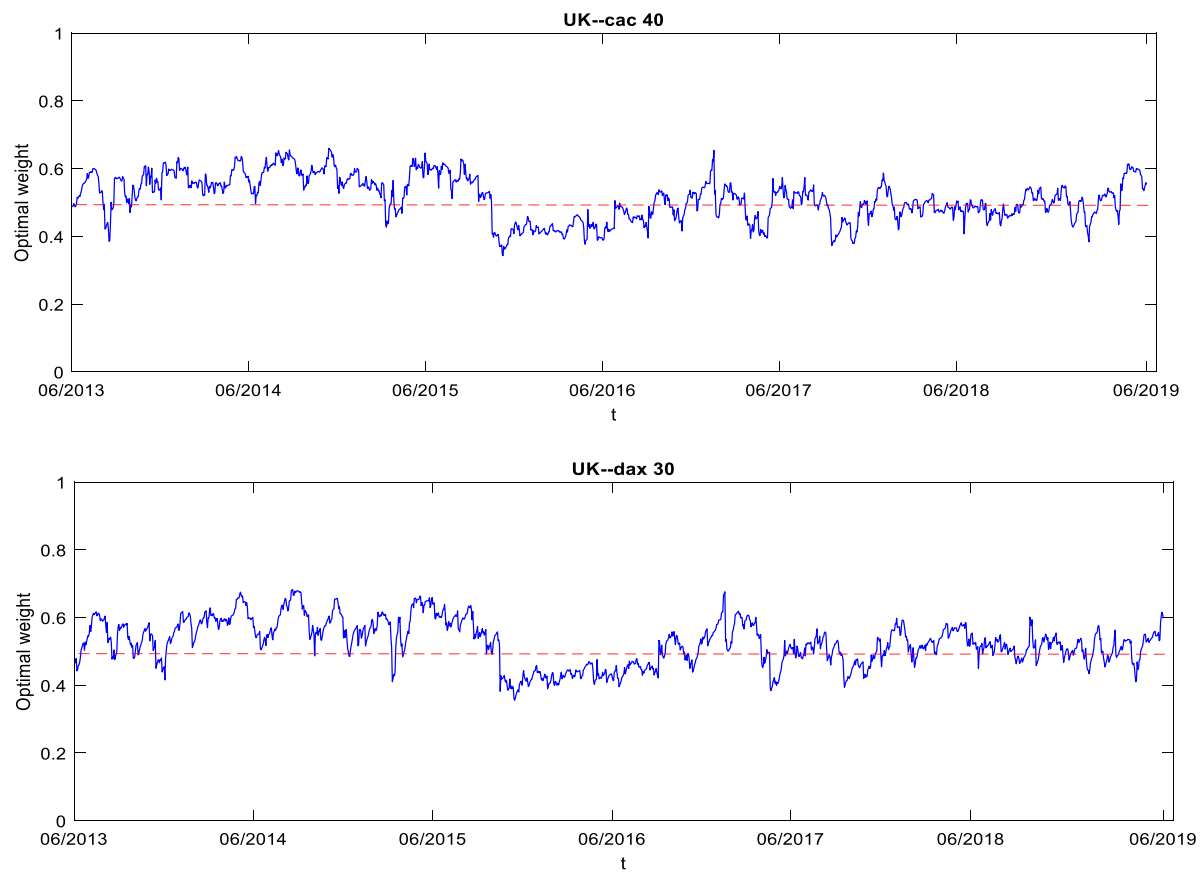

Fig. 8 Optimal weights for the pairs (FTSE100-CAC40) and (FTSE100-DAX30) 
in the markets, with more volatility for the FTSE 100 . The optimal daily weights initiated a decline from the beginning of 2016 due to the volatility of the FTSE 100 in favour of the CAC40 and the DAX 30.

\section{Conclusion}

In this paper we used the approach of Diebold and Yilmaz $(2009,2012)$ to better map the relationship between the three main European markets during the 2013 and 2019 period, which includes the date of the Brexit referendum. We divided our timeframe into two periods: 3 years before the 23rd of June 2016 (pre-Brexit period) and 3 years after this date (post-Brexit period). Our findings show that the highest level of the total spillover index for returns and volatility is consistently observed around polling day. Throughout this period, volatility and total spillover increased in accordance with news releases about Brexit, such as the negotiations regarding the future relationship between the EU and the United Kingdom. On June 12, 2018, the parliamentary process regarding the "withdrawal law" led to a period of uncertainty with the onset of the "parliamentary ping-pong" episode, but also the fact that no compromise was reached on the Irish border issue, leading to a new chapter of volatility in all three markets.

\section{References}

Alter, A., \& Beyer, A. (2014). The dynamics of spillover effects during the European sovereign debt turmoil. Journal of Banking \& Finance, 42, 134-153.

Aristeidis, S., \& Elias, K. (2018). Empirical analysis of market reactions to the UK's referendum resultsHow strong will Brexit be? Journal of International Financial Markets Institutions \& Money, 53, 263-286.

Arshanapalli, B., \& Doukas, J. (1993). International stock market linkages: Evidence from the pre-and postOctober 1987 period. Journal of Banking and Finance, 17, 193-208.

Bekaert, G., Harvey, C. R., \& Ng, A. (2005). Market integration and contagion. Journal of Business, 78, 39-69.

Belke, A., Dubova, I., \& Osowski, T. (2018). Policy uncertainty and international financial markets: The case of Brexit. Applied Economics, 50, 1466-4283.

Billio, M., Getmansky, M., Lo, A. W., \& Pelizzon, L. (2012). Econometric measures of connectedness and systemic risk in the finance and insurance sectors. Journal of Financial Economics, 104, 535-559.

Chen, Y. T. (2001). Testing conditional symmetry with an application to stock returns. Taipei: Institute for Social Science and Philosophy Academia Sinica.

Chen, Y. T., \& Kuan, C. M. (2002). Time irreversibility and EGARCH effects in US stock index returns. Journal of Applied Econometrics, 17(5), 565-578.

Diebold, F. X., \& Yilmaz, K. (2009). Measuring financial asset return and volatility spillovers, with application to global equity markets. The Economic Journal, 119(534), 158-171.

Diebold, F. X., \& Yilmaz, K. (2012). Better to give than to receive: Predictive directional measurement of volatility spillovers. International Journal of Forecasting, 28(1), 57-66.

Fetzer, T. (2019). Did austerity cause Brexit? American Economic Review, 109(11), 3849-3886.

Forbes, K. J., \& Rigobon, R. (2002). No contagion, only interdependence: Measuring stock market comovements. Journal of Finance, 57, 2223-2261.

Jawadi, F., Louhichi, W., \& Idi Cheffou, A. (2015). Intraday bidirectional volatility spillover across international stock markets: Does the global financial crisis matter? Applied Economics, 47(34-35), 3633-3650.

King, M. A., \& Wadhwani, S. (1990). Transmission of volatility between stock markets. Review of Financial Studies, 3(1), 5-33.

Koop, G., Pesaran, M. H., \& Potter, S. M. (1996). Impulse response analysis in non-linear multivariate models. Journal of Econometrics, 74, 119-147. 
Kroner, K., \& Ng, V. (1998). Modelling asymmetric movements of asset prices. Review of Financial Study, 11, 844-871.

Pesaran, M. H., \& Shin, Y. (1998). Generalized impulse response analysis in linear multivariate models. Economics Letters, 58, 17-29.

Poon, S. H., \& Granger, C. (2003). Forecasting volatility in financial markets: A review. Journal of Economic Literature, 41(2), 478-539.

Pukthuanthong, K., \& Roll, R. (2009). Global market integration: An alternative measure and its application. Journal of Financial Economics, 94(2), 214-232.

Yang, J., Kolari, J. W., \& Min, I. (2003). Stock market integration and financial crises: The case of Asia. Applied Financial Economics, 13, 477-486.

Publisher's Note Springer Nature remains neutral with regard to jurisdictional claims in published maps and institutional affiliations. 